\title{
Brain Oxytocin Correlates with Maternal Aggression: Link to Anxiety
}

\author{
Oliver J. Bosch, ${ }^{1}$ Simone L. Meddle, ${ }^{2}$ Daniela I. Beiderbeck, ${ }^{1}$ Alison J. Douglas, ${ }^{2}$ and Inga D. Neumann ${ }^{1}$ \\ ${ }^{1}$ Institute of Zoology, University of Regensburg, 93040 Regensburg, Germany, and ${ }^{2}$ College of Medicine and Veterinary Medicine, Centre for Integrative \\ Physiology, The University of Edinburgh, Edinburgh EH8 9XD, United Kingdom
}

The oxytocinergic system is critically involved in the regulation of maternal behavior, which includes maternal aggression. Because aggression has been linked to anxiety, we investigated the maternal aggression and the role of brain oxytocin in lactating Wistar rats selectively bred for high anxiety-related behavior (HAB) or low anxiety-related behavior (LAB) during the 10 min maternal defense test. HAB dams displayed more maternal aggression against a virgin intruder compared with LAB dams, resulting in more defensive behavior and higher anxiety of HAB-defeated virgins. The different levels of aggression were accompanied by opposite oxytocin release patterns within the paraventricular nucleus (PVN; HAB, increase; LAB, decrease). Furthermore, oxytocin release was higher within the central nucleus of the amygdala ( $\mathrm{CeA}$ ) of HAB dams compared with LABs. A direct correlation between the offensive behavior displayed during the maternal defense test and local oxytocin release was found in both the PVN and CeA. Using retrodialysis, blockade of endogenous oxytocin action by infusion of an oxytocin receptor antagonist (des- $\mathrm{Gly}_{-} \mathrm{NH}_{2}, \mathrm{~d}\left(\mathrm{CH}_{2}\right)_{5}\left[\mathrm{Tyr}(\mathrm{Me})^{2}, \mathrm{Thr}^{4}\right]$ OVT) into the PVN or CeA reduced maternal aggression of $\mathrm{HAB}$ dams, whereas infusion of synthetic oxytocin into the PVN tended to increase aggression toward the intruder in LAB dams. There were no significant differences in oxytocin receptor mRNA expression or oxytocin receptor binding between lactating $\mathrm{HAB}$ and $\mathrm{LAB}$ dams. Therefore, differences in intracerebral release patterns of oxytocin, rather than differences at the level of oxytocin receptors, are critical for the regulation of maternal aggressive behavior.

Key words: microdialysis; stress; paraventricular nucleus; central nucleus of the amygdala; receptor; oxytocin

\section{Introduction}

Enhanced aggressive behavior toward an intruder is part of the complex pattern of maternal behavior in most mammals (Erskine et al., 1978; Numan, 1994; Rosenblatt et al., 1994; Numan and Insel, 2003). Oxytocin, thought to originate from centrally projecting paraventricular nucleus (PVN) neurons, is one of the key neuropeptides regulating the initiation and maintenance of maternal behavior (Pedersen and Boccia, 2002; Numan and Insel, 2003). However, the neuropeptidergic regulation of maternal aggression, specifically, is less clear and even partly controversial. Electrolytic lesions of the PVN reduced maternal aggression (Consiglio and Lucion, 1996), and enhanced oxytocin release was recently reported within the PVN of lactating Wistar rats during the maternal defense test (Bosch et al., 2004). Also, pharmacological manipulation of the oxytocin system within the central nucleus of the amygdala (CeA) or the parvocellular division of the PVN elicits changes in maternal aggression (Giovenardi et al., 1998; Johns et al., 1998; Elliott et al., 2001; Lubin et al., 2003).

Received Dec. 23, 2004; revised May 24, 2005; accepted June 12, 2005.

This work was supported by the Deutsche Forschungsgemeinschaft (I.D.N.), Volkswagen-Stiftung (I.D.N.), Deutscher Akademischer Austausch Dienst/British Council, and The Wellcome Trust (A.J.D., S.L.M.). We are grateful to Dr. R. Landgraf for radioimmunological quantification of oxytocin, to Dr. M. Manning for his generous gift of the oxytocin receptor antagonist, and to Dr. P. Burbach for providing the oxytocin receptor CDNA. We also thank V. Bishop, A. Tweed, M. Fuchs, G. Schindler, K. Sharer, and M. Waldherr for excellent technical help.

Correspondence should be addressed to Dr. Inga D. Neumann, Department of Zoology, University of Regensburg, 93040 Regensburg, Germany. E-mail: inga.neumann@biologie.uni-regensburg.de.

D0I:10.1523/JNEUROSCI.1342-05.2005

Copyright $\odot 2005$ Society for Neuroscience $\quad$ 0270-6474/05/256807-09\$15.00/0
In males, aggressive behavior was found to be inversely related to anxiety-like behavior (Nyberg et al., 2003; Veenema et al., 2004), but less is known about the relationship between anxiety and maternal aggression in lactating females. Therefore, we sought to reveal whether the dam's innate level of anxiety determines the intensity of its maternal aggressive behavior during the maternal defense test and whether the aggression perceived also alters the state of anxiety of the virgin intruder. Experiments were performed on rats selectively bred for extremes in emotionality [i.e., for high anxiety-related behavior (HAB) and low anxietyrelated behavior (LAB)] (Liebsch et al., 1998; Landgraf and Wigger, 2002). Robust behavioral differences between $\mathrm{HAB}$ and $\mathrm{LAB}$ rats are seen not only in emotional (Henniger et al., 2000; Ohl et al., 2001) but also social (Henniger et al., 2000) and male aggressive (Veenema et al., 2004) behaviors. Importantly, in female $\mathrm{HAB}$ and LAB rats, the differences in inborn anxiety persist in pregnancy (Neumann et al., 1998) and during lactation (Neumann, 2003).

Furthermore, we investigated whether the activity of the brain oxytocin system of lactating $\mathrm{HAB}$ and LAB dams correlates with the level of maternal aggressive behavior displayed. We therefore monitored the dynamics of local oxytocin release during the maternal defense test within both the PVN and the CeA using intracerebral microdialysis. The PVN and CeA were examined because of their roles in emotional and neuroendocrine stress responses (Gray et al., 1989; Feldman and Weidenfeld, 1995; Herman and Cullinan, 1997; Neumann et al., 2000a; Vyas et al., 2003; 
Salome et al., 2004) including anxiety (Liebsch et al., 1995; Bale et al., 2001; Davis and Whalen, 2001), maternal behavior, and aggression (Insel and Harbaugh, 1989; Elliott et al., 2001; Lubin et al., 2003; Bosch et al., 2004). We also compared the behavioral consequences of manipulating local oxytocin actions by retrodialysis of either an oxytocin receptor antagonist or of synthetic oxytocin. Last, we determined whether differences in local oxytocin receptor expression or binding might also contribute to the observed differences in maternal aggression found in lactating $\mathrm{HAB}$ and $\mathrm{LAB}$ dams.

\section{Materials and Methods \\ Animals}

All surgical, sampling, and behavioral protocols were approved by the Committee on Animal Health and Care of the local governmental administration and are in accordance with the Guide for the Care and Use of Laboratory Animals by the National Institutes of Health. The bidirectional selection and breeding of HAB and LAB Wistar rats (outbreeding) have been reviewed recently (Landgraf and Wigger, 2002). Both rat lines were treated identically in terms of care, mating, and behavioral testing over the last 10 years.

Virgin female rats (body weight, 250-280 g) selectively bred for HAB or LAB on the elevated plus-maze were mated, and pregnancy was confirmed the next day by the presence of sperm in the vaginal smears (pregnancy day 1). Pregnant rats were housed in groups of four in standard rat cages $(40 \times 60 \times 20 \mathrm{~cm})$; from day 18 of pregnancy, rats were housed individually. On day 22 or 23 of pregnancy, the females delivered $8-16$ pups, and litters were culled to eight pups. The number of pups delivered did not differ between HAB and LAB dams. Rats were kept under standard laboratory conditions ( $12 \mathrm{~h} \mathrm{light/dark} \mathrm{cycle;} \mathrm{lights} \mathrm{on} \mathrm{at}$ 6:00 A.M.; $22^{\circ} \mathrm{C} ; 60 \%$ humidity; and ad libitum access to water and standard rat chow). All behavioral tests were performed on day 3 of lactation.

Maternal defense test. To compare maternal aggressive behavior, the maternal defense test was performed with lactating $\mathrm{HAB}$ and LAB residents and virgin intruders (Wistar rats unselected for anxiety; body weight, 230-250 g; Charles River, Sulzfeld, Germany) between 10:00 A.M. and 12:00 P.M. The intruder was placed into the resident's cage for $10 \mathrm{~min}$ in the presence of the pups, and the behavior was recorded by a digital camera. Later, the offensive (attacks, lateral threats, genital sniffing after attack, offensive sniffing), defensive (freezing, immobility after attack), explorative (rearing, sniffing at opponent, cage exploration), and maternal (nursing, licking/grooming pups, pup carrying) behaviors displayed by the resident and the intruder were analyzed every $10 \mathrm{~s}$ on a videotape by an experienced observer blind to the breeding line or treatment (Neumann et al., 2001). After the 10 min testing period, the virgin intruder was returned to its home cage.

Elevated plus-maze. To confirm differences in the level of anxiety of the residents and to evaluate the possible consequences of exposure to a $\mathrm{HAB}$ or LAB resident on the anxiety-related behavior of the intruders, lactating residents and virgin intruders were tested on the elevated plus-maze $10 \mathrm{~min}$ after termination of the maternal defense test. The intruders were compared with a group of naive (i.e., nondefeated) female virgin rats (Charles River). On the elevated plus-maze, a conflict situation is created between the rat's exploratory drive and its innate fear of open and exposed areas (Pellow et al., 1985; Liebsch et al., 1998). The plus-maze is built of an elevated $(80 \mathrm{~cm}$ ) plus-shaped platform with two closed (with $40 \mathrm{~cm}$ high walls; 20 lux) and two open (each $50 \times 10 \mathrm{~cm}$; 80 lux) arms, connected at the center by a neutral zone $(10 \times 10 \mathrm{~cm})$. The surface of the maze was cleaned with water containing a low concentration of a detergent and dried before each rat was tested. The rat was placed in the neutral zone with its head facing a closed arm. The following parameters were recorded with a video/computer system (Plus-maze version 2.0; Ernst Fricke) during the 5 min exposure: (1) percentage of entries into open arms versus entries into all arms, (2) percentage of time spent on the open arms versus total time, (3) latency until first entry into the open arm, and (4) the number of full entries.

\section{Implantation of microdialysis probes}

On day 1 postpartum, lactating rats were stereotaxically implanted with a U-shaped microdialysis probe (dialysis membrane; molecular cutoff of 18 kDa; Hemophan; Gambro Dialysatoren, Hechingen, Germany) (for details, see Neumann et al., 1993) under isoflurane anesthesia and temperature-controlled conditions using sterile procedures. The microdialysis probes were used either for monitoring local oxytocin release or for manipulation of the local oxytocin system by retrodialysis of synthetic oxytocin or an oxytocin receptor antagonist. The target area was either the PVN [stereotaxic coordinates relative to bregma, $1.6 \mathrm{~mm}$ caudal, 1.8 $\mathrm{mm}$ lateral to midline, $9.1 \mathrm{~mm}$ beneath the surface of the skull; angle of $10^{\circ}$ to avoid sagittal sinus damage; nose, $-3.5 \mathrm{~mm}$ (Paxinos and Watson, $1998)$ ] or the CeA (2.5 mm caudal, $4.0 \mathrm{~mm}$ lateral, $8.5 \mathrm{~mm}$ deep). Unilateral implantation was performed for microdialysis studies, and bilateral implantation was performed for retrodialysis studies. Before the implantation, the probes were flushed and filled with sterile Ringer's solution [composed of the following (in $\mathrm{mm}$ ): $147.1 \mathrm{Na}^{+}, 2.25 \mathrm{Ca}^{2+}, 4$ $\mathrm{K}^{+}, 155.6 \mathrm{Cl}^{-}$, $\mathrm{pH}$ 7.4] (Fresenius, Bad Homburg, Germany). They were secured in place with dental cement to two stainless-steel screws inserted into the skull. Afterward, the inflow and outflow ends of the probe were each attached to short PE-20 polyethylene tubing ( $5 \mathrm{~cm}$ long) filled with Ringer's solution. After surgery, the rats received a $30 \mu \mathrm{l}$ subcutaneous depot injection of antibiotic (Tardomyocel; Bayer, Leverkusen, Germany). Rats were kept together with their litters in polycarbon observation cages $(38 \times 22 \times 35 \mathrm{~cm})$. The next day, they were handled carefully to habituate them to the microdialysis procedure and to reduce nonspecific stress responses during the experiment.

\section{Monitoring of oxytocin release within the PVN or CeA and maternal aggressive behavior}

Two days after surgery at 8:00 A.M., the inflow tubing of the microdialysis probe located within either the PVN or the CeA was connected to a syringe mounted onto a microinfusion pump via a long piece of PE-20 tubing. The outflow was equipped with a tube holder that allowed direct sample collection into a $1.5 \mathrm{ml}$ Eppendorf (Eppendorf, Hamburg, Germany) tube (containing $10 \mu \mathrm{l}$ of $0.1 \mathrm{~N} \mathrm{HCl}$ ) at a distance of $5 \mathrm{~cm}$ above the neck of the animal with a calculated dead space of $12 \mu \mathrm{l}$ and a sampling delay of $3.5 \mathrm{~min}$. The microdialysis probes were perfused at a rate of $3.3 \mu \mathrm{l} / \mathrm{min}$ with sterile Ringer's solution, $\mathrm{pH} 7.4$, initially for $2 \mathrm{~h}$ before the first sample collection. The following five consecutive $30 \mathrm{~min}$ dialysates were collected from the lactating rat: samples 1 and 2 were taken under basal (undisturbed) conditions. During the collection of sample 3, the maternal defense test was performed for $10 \mathrm{~min}$ as described above with continued microdialysis, after which the intruder was removed. Samples 4 and 5 were again taken under undisturbed conditions. Microdialysates were immediately frozen on dry ice and stored at $-20^{\circ} \mathrm{C}$ until quantification of oxytocin by radioimmunoassay. In five dams of each breeding line, maternal aggressive behavior was monitored simultaneously with ongoing microdialysis in the PVN or CeA.

\section{Infusion of an oxytocin receptor antagonist into the PVN or the CeA of HAB dams and monitoring of maternal} aggressive behavior

Lactating HAB dams were prepared for retrodialysis as described above with microdialysis probes implanted bilaterally into either the PVN or the CeA. The probes were perfused at a rate of $1.0 \mu \mathrm{l} / \mathrm{min}$ with sterile Ringer's solution (vehicle; $\mathrm{pH} 7.4$ ) initially for $2 \mathrm{~h}$ before the experiment. At $35 \mathrm{~min}$ before the $10 \mathrm{~min}$ maternal defense test, the inflow tubing containing the control perfusion solution was exchanged with an inflow tubing containing the selective oxytocin receptor antagonist (des-Gly$\mathrm{NH}_{2}, \mathrm{~d}\left(\mathrm{CH}_{2}\right)_{5}\left[\mathrm{Tyr}(\mathrm{Me})^{2}, \mathrm{Thr}^{4}\right]$ OVT; $10 \mu \mathrm{g} / \mathrm{ml}$ dissolved in Ringer's solution) (Manning et al., 1989) in a concentration that was found to be effective in previous experiments (Neumann et al., 2000c; Ebner et al., 2005). The delay for the drug to reach the target site was calculated as 8 min. During the retrodialysis period, an amount of at least $2 \mathrm{ng}$ is expected to be locally delivered into the surrounding tissue as estimated in vitro (Engelmann et al., 1992). In controls with continued perfusion with vehicle, exchange of tubings was mimicked to provide identical experimental conditions for both groups. Perfusion with oxytocin receptor 
antagonist or vehicle was continued during the maternal defense test. The behavioral performance of the resident rat during the maternal defense test was monitored every $10 \mathrm{~s}$ as described above by an experienced observer unfamiliar with the rat's treatment.

\section{Infusion of synthetic oxytocin into the PVN of LAB dams and} monitoring of maternal aggressive behavior

Because reduced release of oxytocin within the PVN was found in LAB residents during the defense of the pups, lactating LAB dams were prepared for retrodialysis within the left and right PVN as described above. At $30 \mathrm{~min}$ before the maternal defense test, the perfusion fluid was either changed to synthetic oxytocin $(1 \mu \mathrm{g} / \mathrm{ml}$ dissolved in Ringer's solution; Sigma, Taufkirchen, Germany) or remained unchanged (vehicle controls). The behavior of the resident rat during the 10 min maternal defense test performed during ongoing retrodialysis was monitored every $10 \mathrm{~s}$ as described above.

\section{Histology}

At the end of the microdialysis experiments, rats were killed with an overdose of isoflurane. The brains were removed, quickly frozen in prechilled $n$-methylbutane on dry ice, and stored at $-70^{\circ} \mathrm{C}$. To histologically verify the placement of the probe in either the PVN or CeA our outside the targeted region (see Figs. 3, 5, 6), brains were cut into $25 \mu \mathrm{m}$ coronal cryostat sections and stained with cresyl violet. Data from experimental subjects were only included in the statistical analysis if the microdialysis probes were correctly placed in the brain target region.

\section{Radioimmunoassay of oxytocin}

Oxytocin content was measured in lyophilized dialysates by a highly sensitive and selective radioimmunoassay (detection limit, 0.1 pg per sample; cross-reactivity of the antisera with other related peptides was $<7 \%$ ) (for details, see Landgraf et al., 1995).

\section{In situ hybridization for oxytocin receptor $m R N A$}

The brains of day 5/6 lactating HAB and LAB dams were removed after decapitation, frozen in prechilled $n$-methylbutane on dry ice, and stored at $-70^{\circ} \mathrm{C}$.

Preparation of oxytocin receptor probe. A $400 \mathrm{bp}$ fragment encoding the $5^{\prime}$-untranslated region of rat oxytocin receptor cDNA was subcloned into pGEM-7Z. Sense and antisense riboprobes were generated by in vitro transcription, in the presence of ${ }^{35} \mathrm{~S}-\mathrm{UTP}$, with SP6- and T7-RNA polymerase after plasmid linearization with EcoRI or BamHI, respectively.

In situ hybridization histochemistry for oxytocin receptor expression. Whole brains were sectioned coronally at $15 \mu \mathrm{m}$ on a cryostat and thaw mounted onto clean poly-L-lysine-coated glass microscope slides and stored at $-70^{\circ} \mathrm{C}$. Every fifth section was mounted separately and stained with toluidine blue (Sigma, Poole, UK) to locate regions of interest. Slide-mounted sections containing the PVN and CeA from each rat were thawed to room temperature (RT) and immersed in $4 \%$ paraformaldehyde solution for $10 \mathrm{~min}$, then rinsed in PBS before treatment with $0.3 \%$ triethanolamine/acetic anhydride. The slides were then rinsed in PBS and dehydrated through a series of graded ethanols. Sections were then incubated at $50^{\circ} \mathrm{C}$ with prehybridization solution for $2 \mathrm{~h}$ and hybridized with the ${ }^{35} \mathrm{~S}$-labeled antisense or sense riboprobe directed against rat oxytocin receptor in a solution mixed with $50 \%$ formamide. The probe was applied to each section at a concentration of $10^{6} \mathrm{cpm}$ per slide in $200 \mu \mathrm{l}$ of hybridization solution for $18 \mathrm{~h}$ at $55^{\circ} \mathrm{C}$ in a humidified chamber. Posthybridization washes consisted of three 5 min washes in $2 \times$ SSC. Sections were then incubated in a $30 \mu \mathrm{g} / \mathrm{ml} \mathrm{RNase-A}$ solution for $1 \mathrm{~h}$ at $37^{\circ} \mathrm{C}$, followed by a $30 \mathrm{~min}$ rinse in $2 \times$ SSC at RT followed by stringency washes in $0.1 \times \mathrm{SSC}$ at $50^{\circ} \mathrm{C}$ for $90 \mathrm{~min}$, then two $60 \mathrm{~min}$ rinses at RT. Test assays were used to determine the optimal wash temperature for this probe. Tissue was then dehydrated in a graded series of ethanol containing 300 $\mathrm{mm}$ ammonium acetate. The hybridization signal was visualized at the cellular level by dipping the slides in autoradiographic emulsion (135 5053; Ilford; Agar Scientific, Stansted, UK). Slides were air dried and stored with desiccant at $4^{\circ} \mathrm{C}$ for 20 weeks before being developed (D19; Eastman Kodak, Rochester, NY), counterstained with hematoxylin and eosin, dehydrated through alcohols to xylene, and finally coverslipped with DPX (a mixture of distyrene, tricresyl phosphate, and xylene) mounting medium (Fisher Scientific, Leicestershire, UK). Slides were examined with a light microscope under bright-field illumination.

Specificity of hybridization signal. Control procedures for the antisense oxytocin receptor probe included hybridization of sections with the sense riboprobe or pretreatment with RNase-A before hybridization with the antisense riboprobe, conducted under identical conditions to those for the antisense probe. There was no detectable hybridization signal with the sense probe or after RNase-A pretreatment.

Quantification of autoradiograms. Anatomical identification of brain structures was based on the stereotaxic brain atlas by Paxinos and Watson (1998). The subdivisions of the PVN into magnocellular and parvocellular cellular parts were defined after Swanson and Kuypers (1980). The slides were coded so that the experimenter was unaware of the treatment of the rats at the time of analysis. Coated section autoradiograms were evaluated by measuring silver grain density over individual neurons within the region of interest $(40 \times$ objective) using a computer-aided image analysis system (Open Lab; Improvision, Lexington, MA). Neurons were considered labeled if the mean number of overlying silver grains was three times greater than that of the equivalent area of background. Background measurements were taken from tissue adjacent to the PVN and CeA that exhibited no evident signal. Silver grain counts were made over 15 randomly chosen labeled neurons per region of interest per section and in four sections per rat. Means were calculated for each variable in each animal; these values were used to calculate group means.

\section{Oxytocin receptor binding autoradiography}

Brain sections from the same rats used for analysis of oxytocin receptor mRNA (above) were also analyzed for oxytocin receptor binding using in situ autoradiography. The oxytocin receptor binding study was performed using a ${ }^{125} \mathrm{I}$-ornithine vasotocin analog $\left({ }^{125} \mathrm{I}-\mathrm{OVTA}\right.$; vasotocin, $\left.\mathrm{d}\left(\mathrm{CH}_{2}\right)_{5}\left[\mathrm{Tyr}(\mathrm{Me})^{2}, \mathrm{Thr}^{4}, \mathrm{Orn}^{8}\right)\left({ }^{125} \mathrm{I}\right) \mathrm{Tyr}^{9}-\mathrm{NH}_{2}\right] ; 2200 \mathrm{Ci} / \mathrm{mmol} ; \mathrm{NEN}$, Boston, MA). Sections were thawed to RT and allowed to dry. Afterward, they were fixed in $0.1 \%$ paraformaldehyde for $2 \mathrm{~min}$ for optimization of tissue integrity. Sections were then rinsed two times in $50 \mathrm{~mm}$ Tris- $\mathrm{HCl}$, $\mathrm{pH} 7.4$, at RT for $10 \mathrm{~min}$ and incubated for $60 \mathrm{~min}$ at RT in a solution of $50 \mathrm{~mm}$ Tris- $\mathrm{HCl}, \mathrm{pH} 7.4$, with $10 \mathrm{~mm} \mathrm{MgCl}, 0.1 \%$ bovine serum albumin, and $50 \mathrm{pm}{ }^{125} \mathrm{I}-\mathrm{OVTA}$. They were then washed three times at RT for 5 min in $50 \mathrm{~mm}$ Tris- $\mathrm{HCl}, \mathrm{pH}$ 7.4, with $10 \mathrm{~mm} \mathrm{MgCl}$, followed by $30 \mathrm{~min}$ rinse in the same buffer. After dipping the slides in distilled $\mathrm{H}_{2} \mathrm{O}$, they were dried rapidly with cold air. Sections were apposed to Kodak BioMaxMR film with ${ }^{125}$ I microscale standards for $72 \mathrm{~h}$. Slides from all groups were processed simultaneously. The autoradiograms were coded to obscure the identity of the tissue. Brain slices that contained comparable sections of the CeA were measured for each subject to provide individual means. Autoradiographic ${ }^{125} \mathrm{I}$-receptor binding was quantified on the film in the CeA as gray density per area minus background using the NIH Image program (ImageJ 1.31; National Institutes of Health; http://rsb.info.nih.gov/ij/). Background activity was automatically subtracted from measured areas to yield values for specific binding.

\section{Statistics}

For the comparison of behavioral parameters during the maternal defense test (see Figs. 1, 5, 6) and on the elevated plus-maze (see Fig. 2), a one-way ANOVA was performed. The microdialysis data of each rat was standardized to the mean of its two basal samples $(=100 \%)$ and presented as mean percentage of the group \pm SEM (see Fig. 3). To compare oxytocin levels in dialysates, a two-way (factors, line-by-time) or oneway (factor, time) ANOVA for repeated measures was used; NewmanKeuls post hoc analysis was performed after significant interaction. Correlation analysis of offensive behavior and oxytocin release was performed using simple regression analysis (see Fig. 4). Mann-Whitney $U$ test was performed for the comparison of mean basal oxytocin levels in dialysates (see Fig. 3) of the behavioral performance of dams retrodialysed with vehicle, oxytocin, or the oxytocin receptor antagonist outside the targeted brain area, of oxytocin receptor mRNA expression, and of oxytocin receptor binding (see Fig. 7). Significance was accepted at $p<$ 0.05 . All statistics were performed using a computer software package (GB-Stat 6.0; Dynamic Microsystems, Silver Spring, MD). 

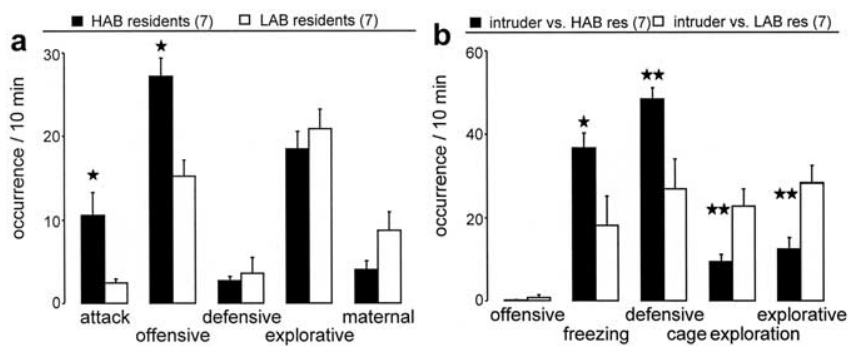

Figure 1. Behavior of $H A B$ and $L A B$ residents $(\boldsymbol{a})$ and their virgin intruders unselected for anxiety $(\boldsymbol{b})$ during the 10 min maternal defense test. $\boldsymbol{a}$, The occurrence of attacks and total offensive behavior as well as total defensive, explorative, and maternal behavior were monitored in $H A B$ and $L A B$ residents on day 3 of lactation. $\boldsymbol{b}$, The occurrence of total offensive, freezing, and total defensive behavior, as well as cage exploration and total explorative behavior, were monitored in the virgin intruder rats. The number of rats included in the statistics was $n=7$ per group. Data are expressed as mean \pm SEM. ${ }^{* *} p<0.01$; ${ }^{*} p<0.05$ versus LAB resident or intruders defeated by $L A B$ residents. res, Residents.
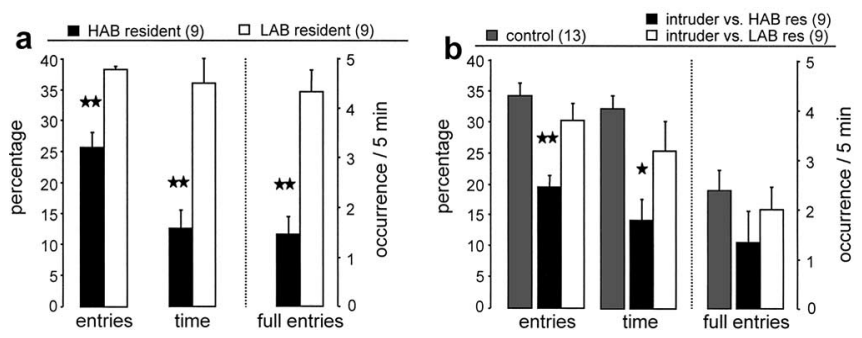

Figure 2. Anxiety-related behavior on the elevated plus-maze of residents and intruders 10 min after termination of the maternal defense test. Comparison of either the lactating $H A B$ and $L A B$ residents $(\boldsymbol{a})$ or the respective virgin intruders (unselected for anxiety) defeated by $H A B$ or $L A B$ residents $(\boldsymbol{b})$ as reflected by the percentage of entries into the open arms of the maze, the percentage of time spent on the open arms of the maze, as well as the total number of full entries into the open arms during a 5 min exposure time. $\ln \boldsymbol{b}$, a group of nondefeated virgin controls is included. The numbers in parentheses indicate group size. Data are expressed as mean \pm SEM. ${ }^{* *} p<0.01 ;{ }^{*} p<0.05$ versus all other groups. res, Residents.

\section{Results}

\section{Comparison of maternal aggressive and anxiety-related} behaviors between $\mathrm{HAB}$ and $\mathrm{LAB}$ dams

During the maternal defense test, $\mathrm{HAB}$ dams displayed significantly more attacks (one-way ANOVA; $F_{(1,12)}=8.51 ; p=0.013$ ) (Fig. 1a) and more overall offensive behavior directed against the virgin intruder $\left(F_{(1,12)}=16.2 ; p=0.002\right)$ than LAB dams. The higher level of maternal aggression in HAB dams was also reflected by a reduced attack latency $(22.7 \pm 11.5 \mathrm{~s})$ compared with LAB dams $\left(120 \pm 36.9 \mathrm{~s} ; F_{(1,12)}=6.28 ; p=0.028\right)$. No significant differences between $\mathrm{HAB}$ and $\mathrm{LAB}$ dams were observed in the amount of defensive, explorative, or maternal behavior displayed during the test period.

$\mathrm{HAB}$ and $\mathrm{LAB}$ residents were tested for anxiety-related behavior on the elevated plus-maze $10 \mathrm{~min}$ after completion of the maternal defense test to confirm their behavioral extremes. As expected, HAB dams explored the open arms of the elevated plusmaze significantly less as reflected by reduced percentage of entries into the open arms (one-way ANOVA; $F_{(1,16)}=29.7 ; p<$ 0.0001 ) (Fig. 2a), reduced percentage of time on the open arms $\left(F_{(1,16)}=20.9 ; p=0.0003\right)$, and less full entries $\left(F_{(1,16)}=24.8\right.$; $p=0.0001)$ when compared with LAB dams.

\section{Effects of exposure to either $\mathrm{HAB}$ or $\mathrm{LAB}$ residents on} defensive behavior and anxiety in virgin intruders

Virgin intruders defeated by $\mathrm{HAB}$ dams displayed significantly more freezing (one-way ANOVA; $F_{(1,12)}=8.2 ; p=0.014$ ) (Fig.
$1 b)$ and more overall defensive behavior $\left(F_{(1,12)}=11.1 ; p=\right.$ $0.006)$ compared with intruders defeated by LAB dams, whereas cage exploration $\left(F_{(1,12)}=13.0 ; p=0.004\right)$ and overall explorative behavior were significantly higher in virgins defeated by LAB dams $\left(F_{(1,12)}=13.1 ; p=0.004\right)$.

The anxiety-related behavior of virgin intruders (commercially obtained and unselected for emotionality) on the elevated plus-maze was dependent on the resident exposed to. Virgin intruders who were defeated by the more aggressive HAB dams were significantly more anxious, because they entered the open arms less frequently $\left(F_{(2,28)}=10.4 ; p=0.0004\right)$ (Fig. $\left.2 b\right)$ and spent less time in the open arms $\left(F_{(2,28)}=7.7 ; p=0.002\right)$ compared with virgin intruders defeated by a LAB dam and to nondefeated virgin controls.

\section{Effect of maternal defense on oxytocin release in HAB and LAB dams \\ PVN}

The oxytocin content in dialysates sampled under basal conditions from the PVN (mean sample 1 and 2) did not differ between lactating $\mathrm{HAB}$ and $\mathrm{LAB}$ rats (one-way ANOVA; factor, line; $\left.F_{(1,12)}=2.24 ; p=0.16\right)$ (Fig. $3 a$, inset). Oxytocin release within the PVN significantly differed between lactating $\mathrm{HAB}$ and $\mathrm{LAB}$ residents (two-way ANOVA for repeated measures; factor, line; $F_{(1,52)}=6.20 ; p=0.03$ ) (Fig. 3a), although it did not change significantly over time (factor, time; $F_{(4,44)}=0.53 ; p=0.72$ ). However, when performing a one-way ANOVA for repeated measures separately on data from each group, a significant time effect could be found in both $\operatorname{HAB}\left(F_{(4,56)}=8.91 ; p<0.0001\right)$ and $\operatorname{LAB}\left(F_{(4,56)}=13.0 ; p<0.0001\right)$ dams. Oxytocin release within the PVN increased in $\mathrm{HAB}(p<0.01$ vs sample 2$)$ but decreased in LAB residents ( $p<0.01$ vs sample 2 ) during exposure to the maternal defense test. Differences in local oxytocin release were also reflected by significant differences in $\delta$ values between HAB and LAB dams ( $p=0.002)$ (Fig. $3 a$, inset). Importantly, oxytocin content in microdialysates sampled outside the PVN remained at basal levels during exposure to maternal defense, at least in LAB dams (Fig. 3a).

The amount of offensive behavior displayed by the HAB and LAB dams did correlate with the oxytocin release within the PVN $\left(r^{2}=0.56 ; p=0.005\right)($ Fig. $4 a)$.

\section{CeA}

Under basal conditions, oxytocin content in the dialysates from the CeA did not significantly differ between lactating $\mathrm{HAB}$ and LAB residents (one-way ANOVA; factor, line; $F_{(1,10)}=0.75 ; p=$ $0.41)$ (Fig. $3 b$, inset). Oxytocin release within the CeA changed significantly over time (two-way ANOVA for repeated measures; factor, time; $F_{(4,36)}=4.11 ; p=0.008$ ) (Fig. $3 b$ ) but was not different between lactating $\mathrm{HAB}$ and $\mathrm{LAB}$ residents (factor, line; $\left.F_{(1,44)}=1.05 ; p=0.33\right)$. During the maternal defense test, the oxytocin content increased significantly in dialysate sample 3 compared with sample 2 of both $\mathrm{HAB}(p<0.001)$ and LAB $(p<$ 0.05 ) dams. When performing statistics on the oxytocin content in sample 3 , there was a trend toward higher oxytocin content in $\mathrm{HAB}$ compared with LAB rats during maternal defense ( $p=$ $0.06)$ (Fig. $3 b$, inset). Oxytocin content in microdialysates sampled outside the CeA during maternal defense was unchanged compared with basal levels (Fig. 3b).

The amount of offensive behavior displayed by the HAB and LAB dams did correlate with the oxytocin release within the CeA $\left(r^{2}=0.67 ; p=0.004\right)$ (Fig. $\left.4 b\right)$. 


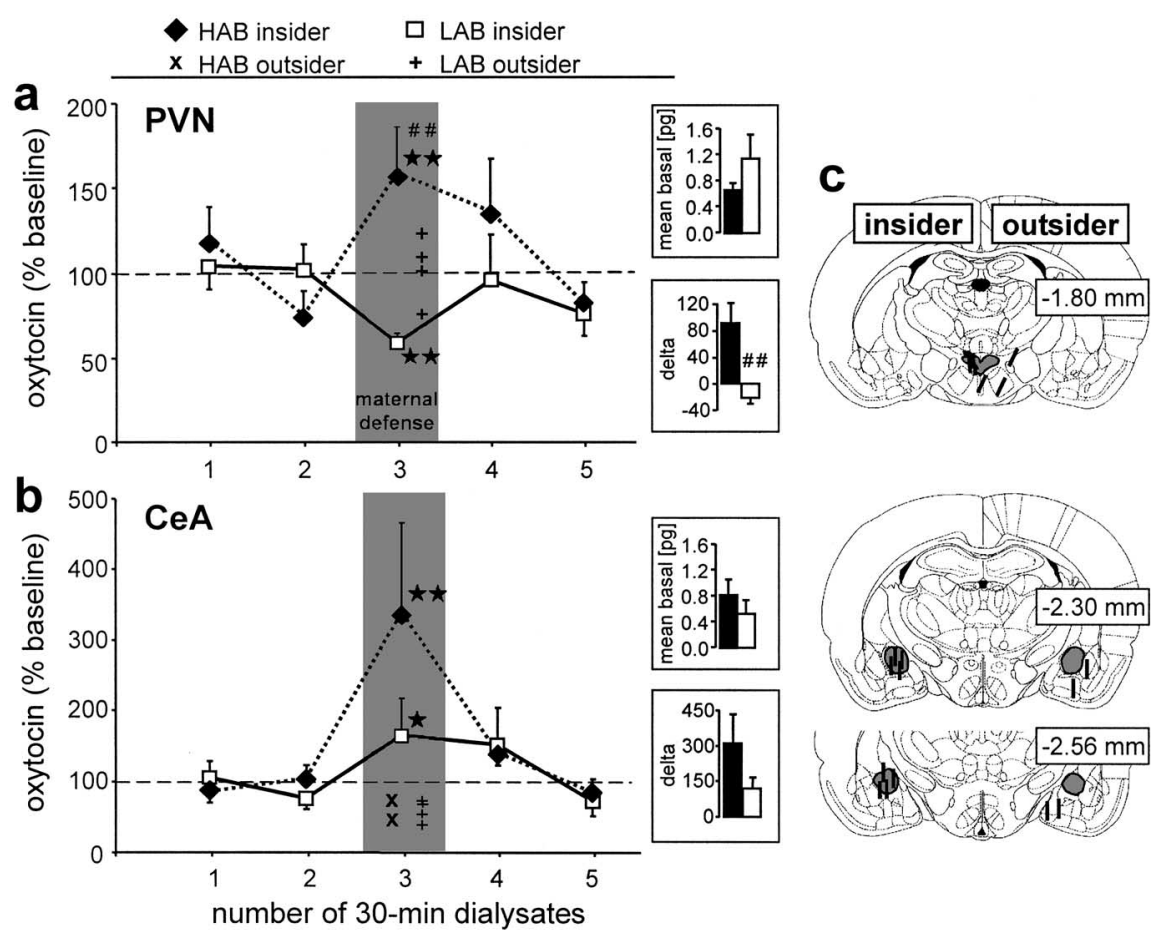

Figure 3. Oxytocin release within the PVN $(\boldsymbol{a})$ and the $C e A(\boldsymbol{b})$ of lactating $H A B$ and $L A B$ residents in response to maternal defense and exemplary reconstructions of the exact placement of the microdialysis probes inside ("insider") or outside ("outsider") the target area drawn on to plates from the Paxinos and Watson (1998) atlas. Thirty minute dialysates were sampled under basal conditions (samples 1 and 2). During the third dialysis sampling period, a virgin intruder rat was placed into the cage of the lactating resident for $10 \mathrm{~min}$ (maternal defense) with continued microdialysis (insider). Also shown are individual oxytocin contents in sample 3 collected outside the respective target areas (outsider; $\times, \mathrm{HAB} ;+, \mathrm{LAB}$ ). Data are expressed as percentage of baseline (mean of sample 1 and $2 ;=100 \%$; dotted line) \pm SEM. Insets demonstrate mean basal oxytocin (samples 1 and 2 ) content in picograms per $100 \mu \mathrm{l}$ sample and $\delta$ values (sample 3 minus minimum basal). The numbers on the right of each plate indicate the distance in millimeters posterior to bregma. Number of rats included in the statistics: $\boldsymbol{a}$, $H A B$, eight; $L A B, \operatorname{six} ; \boldsymbol{b}, H A B$, six; $L A B$, six. ${ }^{*} p<0.05,{ }^{* *} p<0.01$ versus sample 2 of respective group; ${ }^{\# \#} p<0.01$ versus $L A B$.

amount of defensive $\left(F_{(1,11)}=1.59 ; p=\right.$ 0.23 ) (Fig. 5a), exploratory, and maternal behaviors (data not shown) were unchanged. In contrast, in LAB dams in which local oxytocin release was found to be reduced during the maternal defense test, local administration of the oxytocin receptor antagonist did not alter any behavioral measure (Fig. 5a).

Bilateral retrodialysis application of the oxytocin receptor antagonist closely outside the left and right PVN $(n=3)$ (Fig. $5 d$ ) did not affect the behavioral performance of HAB dams compared with dams treated with vehicle $(n=2)$ outside the target area with respect to the parameters number of attacks, offensive, and defensive behavior (data not shown).

\section{Effects of bilateral administration of synthetic oxytocin into the PVN of LAB dams on maternal aggression}

In LAB dams, local oxytocin release within the PVN was found to be reduced during maternal defense. Retrodialysis of synthetic oxytocin bilaterally into the PVN did not significantly affect the total amount of offensive behavior (factor, treatment; $F_{(1,13)}=2.60 ; p=0.13$ ) (Fig. 6). However, there was a tendency toward an increase in the offensive parameter lateral threat $\left(F_{(1,13)}=4.01 ; p=0.06\right)$.

Bilateral retrodialysis application of oxytocin closely outside the left and right $\operatorname{PVN}(n=2)$ (Fig. $6 b$ ) had no effect on the behavioral performance of LAB dams

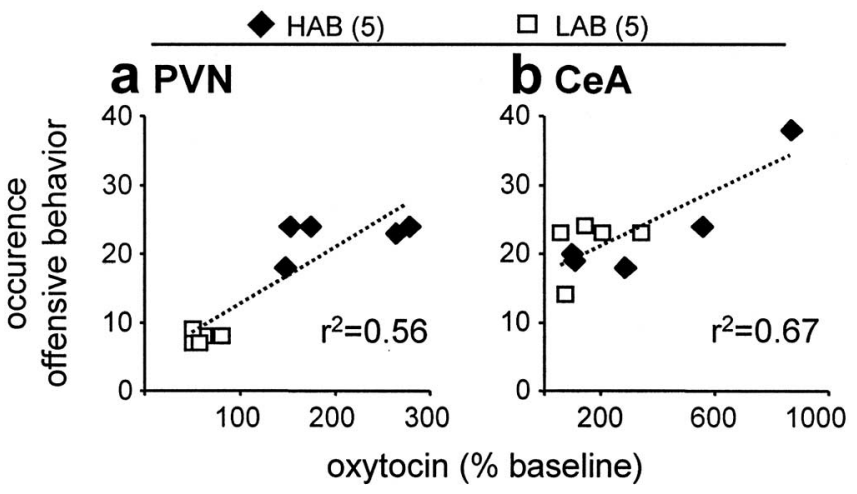

Figure 4. Correlation of maternal aggression with local oxytocin release. The total amount of offensive behavior displayed by the lactating $H A B$ and $L A B$ residents during maternal defense was correlated with the release of oxytocin in either the PVN $(\boldsymbol{a})$ or the $\mathrm{CeA}(\boldsymbol{b})$. The numbers in parentheses indicate group size. Each data point represents one individual dam. The dotted line indicates the regression line.

\section{Effects of administration of an oxytocin receptor antagonist bilaterally into the PVN on maternal aggression}

In $\mathrm{HAB}$ dams, oxytocin release within the PVN was found to be elevated during exposure to the maternal defense (see above). Retrodialysis of the oxytocin receptor antagonist bilaterally into the PVN resulted in a significant reduction in the level of the overall offensive behavior compared with vehicle-treated $\mathrm{HAB}$ dams (factor, treatment; $\left.F_{(1,11)}=5.22 ; p=0.04\right)($ Fig. $5 a)$. The compared with LAB dams treated with vehicle $(n=2)$ outside the target areas with respect to the parameters number of attacks, lateral threat, and offensive and defensive behavior (data not shown).

\section{Effects of administration of an oxytocin receptor antagonist} bilaterally into the $\mathrm{CeA}$ on maternal aggression

Oxytocin release was more pronounced within the CeA of $\mathrm{HAB}$ compared with LAB dams during exposure to the maternal defense (see above). In lactating HAB rats, retrodialysis of the oxytocin receptor antagonist bilaterally into the CeA resulted in a significant decrease in the total amount of attacks (factor, treatment; $F_{(1,14)}=5.65 ; p=0.03$ ) (Fig. $5 b$ ) and offensive behavior $\left(F_{(1,14)}=8.40 ; p=0.012\right)$ compared with vehicle-treated $\mathrm{HAB}$ dams. The defensive, exploratory, and maternal behaviors displayed were unchanged. In contrast, in LAB dams the infusion of the oxytocin receptor antagonist into the CeA did not significantly change any of the behavioral parameters monitored (Fig. 5b).

Furthermore, when the oxytocin receptor antagonist was applied closely outside the left and right CeA by retrodialysis (Fig. $5 d$ ), the behavioral performance (attacks, offensive, and defensive behavior) of HAB $(n=3)$ or LAB $(n=2)$ dams was not altered compared with dams treated with vehicle (HAB, $n=2$; LAB, $n=2$ ) outside the target areas (data not shown). 
Expression of oxytocin receptor mRNA and oxytocin receptor binding

The expression of oxytocin receptor mRNA either in the magnocellular $(p=$ $0.20)$ or the parvocellular $(p=0.58)$ part of the PVN or in the CeA $(p=0.42)$ did not differ significantly between $\mathrm{HAB}$ and LAB dams (Fig. 7a). Oxytocin receptor binding in the CeA did not differ between lactating HAB and LAB dams $(p=0.37)$ (Fig. 7b). However, comparison of the oxytocin receptor $m R N A$ expression in the CeA of all lactating HAB and LAB dams with data pooled from both virgin $\mathrm{HAB}$ and $\mathrm{LAB}$ rats revealed a significant increase of oxytocin receptor mRNA in lactating dams $(p=0.03)$ (Fig. 7a).

\section{Discussion}

We have shown that maternal aggression in lactating rats is dependent on inborn emotionality and correlates with oxytocin release within the brain. During the maternal defense test, $\mathrm{HAB}$ residents were more aggressive than LAB residents, which was also reflected by more defensive postures and an elevated level of anxiety of virgin intruders defeated by HAB dams. In addition, oxytocin release increased within both the PVN and the CeA of lactating $\mathrm{HAB}$ rats during the maternal defense test, whereas it decreased or only slightly increased in LABs. Local infusion of an oxytocin receptor antagonist into either the PVN or the CeA of lactating HAB residents, but not closely outside these target regions, revealed that locally released, endogenous oxytocin supports the high level of maternal aggressive behavior. Likewise, oxytocin infusion into the PVN tended to increase maternal aggression in LAB residents. Oxytocin receptor mRNA expression and binding in the PVN or CeA did not differ between HAB and LAB dams. Thus, differences in the dynamics of oxytocin release patterns within selected brain regions, rather than differences at the level of oxytocin receptors, underlies maternal aggression.

\section{Maternal aggression and anxiety}

Our results from the elevated plus-maze demonstrate that the extremes in anxietyrelated behavior of $\mathrm{HAB}$ and $\mathrm{LAB}$ dams persist in lactation even after exposure to the maternal defense test. Importantly, although more anxious, lactating HAB dams are significantly more protective of their offspring by being more offensive than LAB dams. This is in line with studies on their maternal behavior in which HAB dams spend more time on the nest and collect their pups faster during the pup re-
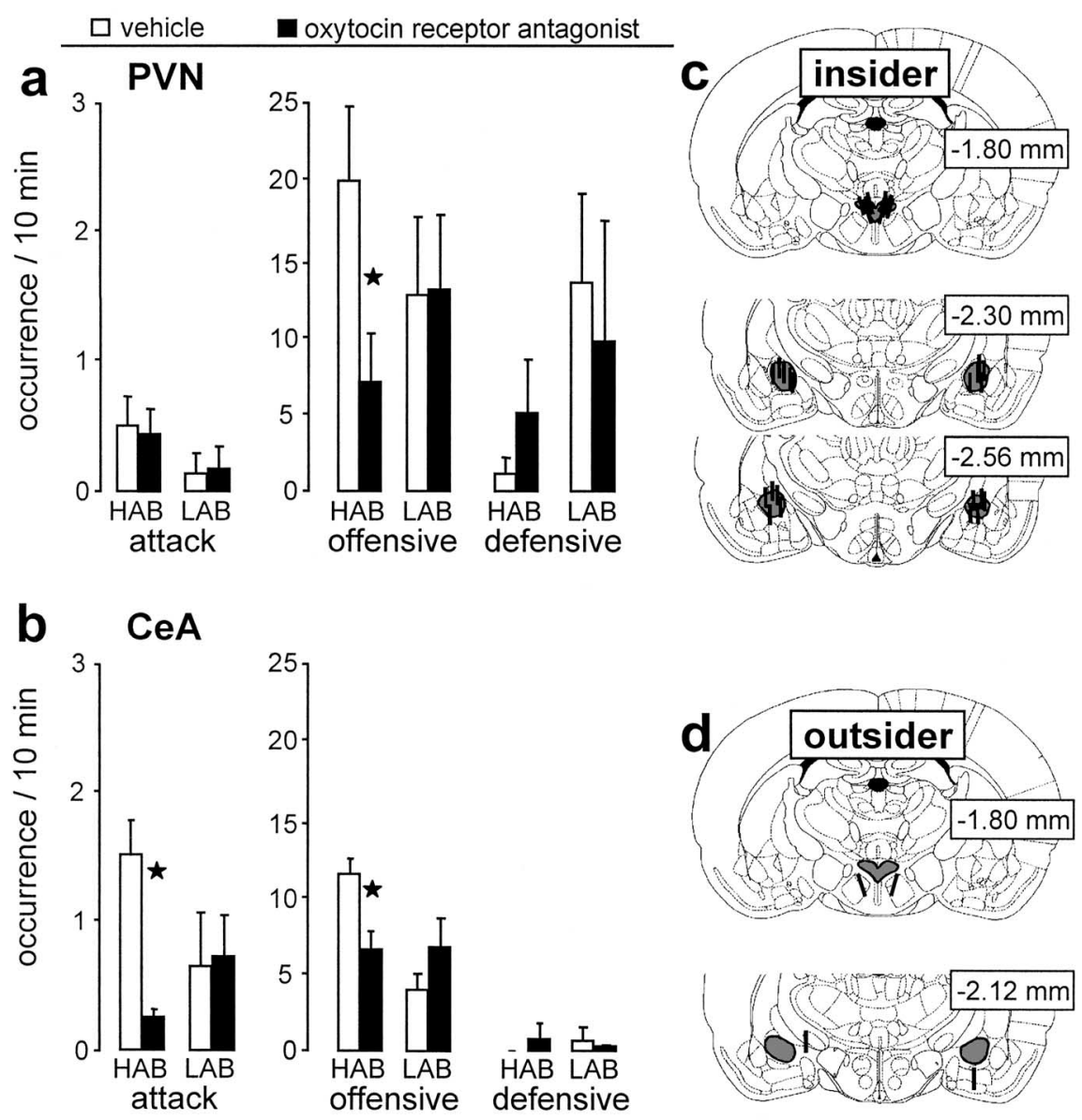

Figure 5. Behavioral consequences of local infusion of the oxytocin receptor antagonist and exemplary reconstructions of the exact placement of the microdialysis probes. The antagonist was applied via retrodialysis bilaterally into (insider) the PVN (a) and the $C$ eA $(\boldsymbol{b})$ of lactating HAB and LAB residents, and the occurrence of attacks, offensive, and defensive behaviors during the $10 \mathrm{~min}$ maternal defense test was monitored. The exact placement of the microdialysis probes inside (insider; $\boldsymbol{c}$ ) or outside (outsider; $\boldsymbol{d}$ ) the target area was drawn on to plates from the Paxinos and Watson (1998) atlas. Number of rats included in the statistics: $\boldsymbol{a}, \mathrm{HAB}$ : VEH, six; OXT-A, eight; LAB: VEH, six; OXT-A, six; $\boldsymbol{b}$, HAB: VEH, seven; OXT-A, eight; LAB: VEH, six; OXT-A, eight. Data are expressed as mean \pm SEM. ${ }^{*} p<0.05$ versus respective vehicle-treated group. VEH, Vehicle; OXT-A, oxytocin receptor antagonist.

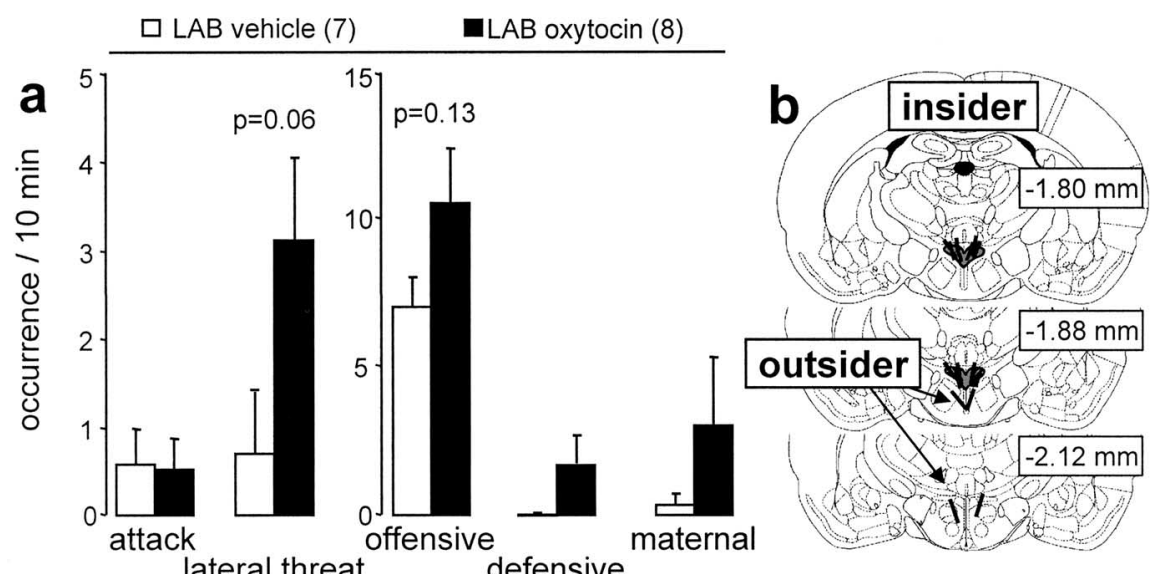

Figure 6. Behavioral consequences of application of synthetic oxytocin or vehicle infused via retrodialysis bilaterally into (insider) the paraventricular nucleus of lactating LAB residents. $\boldsymbol{a}$, The amount of attacks and lateral threats and of offensive, defensive, and maternal behaviors during the 10 min maternal defense test was monitored. $\boldsymbol{b}$, Exemplary reconstructions of the exact placement of the microdialysis probes inside (insider) or outside (outsider) the target area was drawn on to plates from the Paxinos and Watson (1998) atlas. The numbers in parentheses indicate group size. Data are expressed as mean \pm SEM. 


\section{a OXT-R mRNA}

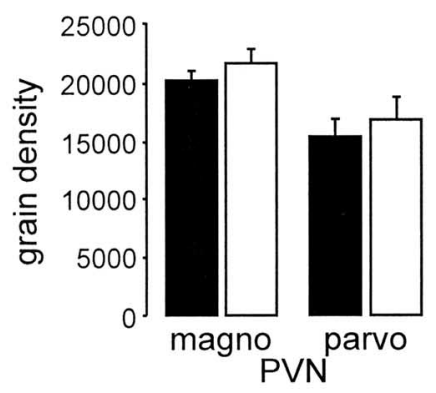

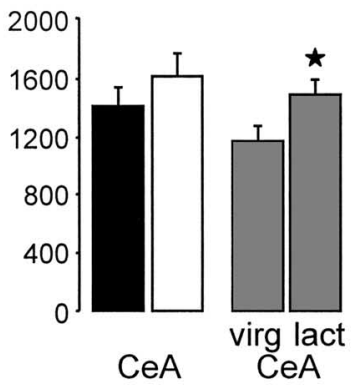

Figure 7. Evaluation of oxytocin receptors. Comparison of oxytocin receptor (OXT-R) mRNA expression in the magnocellular (magno) and parvocellular (parvo) part of the PVN and the CeA of lactating (lact) HAB and LAB dams, as well as of pooled virgin (virg) female $H A B$ and $L A B$ rats versus pooled lactating $H A B$ and $L A B$ rats (gray columns) (a) and OXT-R binding in the CeA of lactating $H A B$ and $L A B$ dams $(\boldsymbol{b})$. The number of rats included in the statistics: lactating, $H A B$, six, $L A B$, eight; pooled $H A B / L A B$, lactating, 15; virgin, 16. Data are expressed as mean \pm SEM. * $p<0.05$ versus pooled virgin group.

trieval test, whereas the occurrence of licking and grooming the offspring is similar in HAB and LAB dams (Neumann et al., 2005). Similarly, mice selected for HAB (Krömer et al., 2005) show a comparable style of maternal behavior during lactation, including more pup-directed behavior and enhanced maternal aggression toward an intruder during the maternal defense test (A. H. Veenema and I. D. Neumann, unpublished observation) as signs of a high level of pup protection. Interestingly, in nonhuman primates, mothers who show frequent behavioral signs of anxiety scored higher in maternal protectiveness, suggesting a link between protective parenting style and emotionality (Maestripieri, 1999). However, our finding of high maternal aggression in rats with high innate level of anxiety-related behavior is contrary to reports in (nonselected, genetically similar) lactating mice that demonstrated the least anxious mice being the most aggressive ones (Maestripieri and D'Amato, 1991; Parmigiani et al., 1999). Similarly, in rats, manipulations that resulted in enhanced emotionality consequently reduced maternal aggressive behavior (Lonstein et al., 1998; Boccia and Pedersen, 2001). In contrast, various neural interventions that decrease aggression do not affect the rats' fearfulness (Hansen and Ferreira, 1986; Ferreira et al., 1987), and separate neuronal regulation of maternal aggression and the animal's fear state has been suggested (Numan and Insel, 2003).

The level of maternal aggression significantly influenced the behavior of the virgin intruder rats. Intruders exposed to $\mathrm{HAB}$ dams not only displayed more defensive behavior during the defense test compared with those exposed to LAB dams but also became more anxious on the plus-maze immediately after the maternal defense test. In males, it has been shown repeatedly that exposure to an aggressive male resident results in enhanced anxiety (Heinrichs et al., 1992; Liebsch et al., 1995; Haller et al., 2003). However, this is the first study demonstrating that exposure to an offensive dam results in the same behavioral phenomenon in virgin female rats and that the increase in anxiety seems to be strictly dependent on the level of aggressive behavior experienced.

\section{Maternal aggression and brain oxytocin}

The amount of aggressive behavior displayed during the maternal defense test correlated with the rise in local oxytocin release both within the PVN and the CeA. In more detail, the level of maternal b oxT-R binding

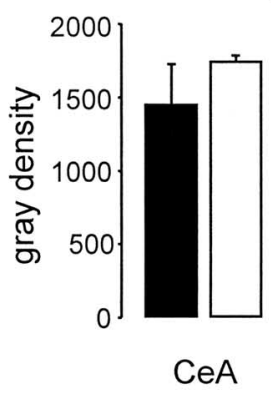

aggression seen in the anxious HAB dams during maternal defense was found to be accompanied by a significant increase in oxytocin release into the extracellular space of the PVN, whereas local oxytocin release decreased in the less aggressive LAB dams. Together with the finding that blockade of oxytocin receptors within the PVN by local administration of a selective oxytocin receptor antagonist reduced maternal aggression in HABs (Fig. 5), our results support the hypothesis that oxytocin release in the PVN is necessary for the display of maternal aggressive behavior. Interestingly, the same treatment did not alter maternal aggressive behavior in LAB dams, which showed a reduced release of endogenous oxytocin within the PVN during pup defense. However, when oxytocin concentrations in the PVN of LAB dams were artificially increased by local retrodialysis of the synthetic neuropeptide, the animals tended to be more aggressive (Fig. 6), further demonstrating a role for oxytocin in the PVN to mediate maternal aggression.

One possible mechanism of oxytocin action in the PVN in regulating maternal aggressive behavior could be via inhibition of the brain corticotropin-releasing hormone (CRH) system. Intracerebral injection of $\mathrm{CRH}$ was shown recently to inhibit aggression in lactating mice, and inhibition of CRH might be necessary for maternal aggression (Gammie et al., 2004). In support of this hypothesis, brain oxytocin inhibits the activity of CRH neurons (Windle et al., 2004), and, specifically, oxytocin released within the PVN inhibits the activity of the hypothalamo-pituitaryadrenal axis (Neumann et al., 2000a), which is driven mainly by $\mathrm{CRH}$ neurons. Our findings are also in agreement with a study by Consiglio and Lucion (1996), who demonstrated that electrolytic lesions of the PVN reduced various components of maternal aggression. In contrast, ibotenic acid lesions of the parvocellular part of the PVN or local inhibition of oxytocin synthesis resulted in increased bite frequency of rat dams against a male intruder (Giovenardi et al., 1998), although in this context the contribution of locally released oxytocin in the PVN or central projection sites remains unknown.

Our results also provide evidence for increased oxytocin release within the $\mathrm{CeA}$ in both $\mathrm{HAB}$ and $\mathrm{LAB}$ dams during maternal defense. This is remarkable, because there is only sparse oxytocinergic innervation and low concentrations of oxytocin in the extracellular space of the amygdala. Monitoring of local oxytocin release has found to be difficult, and oxytocin was only recently reported to be detectable in CeA dialysates (Bosch et al., 2004; Ebner et al., 2005). Oxytocin release within the CeA appeared more pronounced in $\mathrm{HAB}$ compared with $\mathrm{LAB}$ dams during maternal defense, and local administration of the oxytocin receptor antagonist significantly attenuated aggressive behavior in $\mathrm{HAB}$ dams only, whereas it was without effect in LABs. Therefore, we conclude that oxytocin released within the amygdala also contributes to maternal aggression. Interestingly, in lactating Wistar rats unselected for anxiety-related behavior, oxytocin release within the CeA remained unchanged during maternal defense, but they displayed a low level of offensive behavior (unselected, 14\%; HAB, 44\%; LAB, 25\%) (Bosch et al., 2004). Thus, a direct correlation between the level of maternal aggression and the amount of oxytocin released within the CeA is likely and could be 
confirmed in the present study. This is supported by experiments performed in lactating hamsters (Ferris et al., 1992), in which the repeated administration of oxytocin in the CeA resulted in enhanced aggression toward the male intruder. In contrast, local infusion of an oxytocin receptor antagonist $4 \mathrm{~h}$ before testing increased the frequency of attacks against a male intruder rat (Lubin et al., 2003). These results may not be in conflict, because blockade of oxytocin receptors might trigger a rebound effect and, thus, induce even more local oxytocin release after $4 \mathrm{~h}$ (Landgraf and Neumann, 2004). Overall, our findings on brain oxytocin as a mediator of aggression are supported by studies on oxytocin knock-out mice that showed a reduced aggression compared with wild-type mice (Young et al., 1998).

\section{Brain oxytocin and anxiety}

Oxytocin also regulates anxiety-related behavior (McCarthy et al., 1996; Windle et al., 1997; Neumann et al., 2000b; Mantella et al., 2003), an effect that could be localized within the amygdala (Bale et al., 2001; Neumann, 2002). Thus, oxytocin is likely to promote maternal aggressive behavior indirectly via transient regulation of fear and anxiety possibly by regulation of the activity of the brain CRH system (Windle et al., 2004). As another possible mechanism, oxytocin inhibits the release of GABA within the CeA, but not PVN, during maternal aggression in $\mathrm{HAB}$ dams (Neumann and O. J. Bosch, unpublished observation). Thus, it is likely that there is a link between local oxytocin release, the availability of inhibitory or excitatory amino acids within the CeA (Ebner et al., 2005; Huber et al., 2005), the activity of the brain CRH system (Liebsch et al., 1995), the state of anxiety, and the level of maternal aggression (Gammie et al., 2004).

In contrast to differences in local oxytocin release between $\mathrm{HAB}$ and $\mathrm{LAB}$ females, the expression and density of oxytocin receptors within selected brain regions did not differ, and this has also been reported for male rats (Wigger et al., 2004). Enhanced oxytocin receptor mRNA expression (Young et al., 1997), as confirmed in lactating $\mathrm{HAB}$ and $\mathrm{LAB}$ dams (pooled) of this study, and binding (Insel, 1990; Freund-Mercier et al., 1994) in limbic brain areas of lactating rats may, in general, contribute to their complex behavioral adaptations, including an enhanced level of aggression. However, our data suggest that local oxytocin release patterns within the PVN and the CeA, rather than differences at the receptor level, determine the expression of maternal aggressive behavior.

\section{References}

Bale TL, Davis AM, Auger AP, Dorsa DM, McCarthy MM (2001) CNS region-specific oxytocin receptor expression: importance in regulation of anxiety and sex behavior. J Neurosci 21:2546-2552.

Boccia ML, Pedersen CA (2001) Brief vs. long maternal separations in infancy: contrasting relationships with adult maternal behavior and lactation levels of aggression and anxiety. Psychoneuroendocrinology 26:657-672.

Bosch OJ, Krömer SA, Brunton P, Neumann ID (2004) Release of oxytocin in the hypothalamic paraventricular nucleus, but not central amygdala or lateral septum in lactating residents and virgin intruders during maternal defence. Neuroscience 124:439-448.

Consiglio AR, Lucion AB (1996) Lesion of hypothalamic paraventricular nucleus and maternal aggressive behavior in female rats. Physiol Behav 59:591-596.

Davis M, Whalen PJ (2001) The amygdala: vigilance and emotion. Mol Psychiatry 6:13-34

Ebner K, Bosch OJ, Krömer SA, Singewald N, Neumann ID (2005) Release of oxytocin in the rat central amygdala modulates stress-coping behaviour and the release of excitatory amino acids. Neuropsychopharmacology 30:223-230.

Elliott JC, Lubin DA, Walker CH, Johns JM (2001) Acute cocaine alters oxytocin levels in the medial preoptic area and amygdala in lactating rat dams: implications for cocaine-induced changes in maternal behavior and maternal aggression. Neuropeptides 35:127-134.

Engelmann M, Ludwig M, Landgraf R (1992) Microdialysis administration of vasopressin and vasopressin antagonists into the septum during polejumping behavior in rats. Behav Neural Biol 58:51-57.

Erskine MS, Barfield RJ, Goldman BD (1978) Intraspecific fighting during late pregnancy and lactation in rats and effects of litter removal. Behav Biol 23:206-218.

Feldman S, Weidenfeld J (1995) Neural mechanisms involved in the corticosteroid feedback effects on the hypothalamo-pituitary-adrenocortical axis. Prog Neurobiol 45:129-141.

Ferreira A, Dahlof LG, Hansen S (1987) Olfactory mechanisms in the control of maternal aggression, appetite, and fearfulness: effects of lesions to olfactory receptors, mediodorsal thalamic nucleus, and insular prefrontal cortex. Behav Neurosci 101:709-717, 746.

Ferris CF, Foote KB, Meltser HM, Plenby MG, Smith KL, Insel TR (1992) Oxytocin in the amygdala facilitates maternal aggression. Ann NY Acad Sci 652:456-457.

Freund-Mercier MJ, Stoeckel ME, Klein MJ (1994) Oxytocin receptors on oxytocin neurones: histoautoradiographic detection in the lactating rat. J Physiol (Lond) 480:155-161.

Gammie SC, Negron A, Newman SM, Rhodes JS (2004) Corticotropinreleasing factor inhibits maternal aggression in mice. Behav Neurosci 118:805-814.

Giovenardi M, Padoin MJ, Cadore LP, Lucion AB (1998) Hypothalamic paraventricular nucleus modulates maternal aggression in rats: effects of ibotenic acid lesion and oxytocin antisense. Physiol Behav 63:351-359.

Gray TS, Carney ME, Magnuson DJ (1989) Direct projections from the central amygdaloid nucleus to the hypothalamic paraventricular nucleus: possible role in stress-induced adrenocorticotropin release. Neuroendocrinology 50:433-446.

Haller J, Leveleki C, Baranyi J, Mikics E, Bakos N (2003) Stress, social avoidance and anxiolytics: a potential model of stress-induced anxiety. Behav Pharmacol 14:439-446.

Hansen S, Ferreira A (1986) Food intake, aggression, and fear behavior in the mother rat: control by neural systems concerned with milk ejection and maternal behavior. Behav Neurosci 100:64-70.

Heinrichs SC, Pich EM, Miczek KA, Britton KT, Koob GF (1992) Corticotropin-releasing factor antagonist reduces emotionality in socially defeated rats via direct neurotropic action. Brain Res 581:190-197.

Henniger MS, Ohl F, Holter SM, Weissenbacher P, Toschi N, Lorscher P, Wigger A, Spanagel R, Landgraf R (2000) Unconditioned anxiety and social behaviour in two rat lines selectively bred for high and low anxietyrelated behaviour. Behav Brain Res 111:153-163.

Herman JP, Cullinan WE (1997) Neurocircuitry of stress: central control of the hypothalamo-pituitary-adrenocortical axis. Trends Neurosci 20:78-84.

Huber D, Veinante P, Stoop R (2005) Vasopressin and oxytocin excite distinct neuronal populations in the central amygdala. Science 308:245-248.

Insel TR (1990) Regional changes in brain oxytocin receptors post-partum: time-course and relationship to maternal behaviour. J Neuroendocrinol 2:539-545.

Insel TR, Harbaugh CR (1989) Lesions of the hypothalamic paraventricular nucleus disrupt the initiation of maternal behavior. Physiol Behav 45:1033-1041.

Johns JM, Noonan LR, Zimmerman LI, McMillen BA, Means LW, Walker CH, Lubin DA, Meter KE, Nelson CJ, Pedersen CA, Mason GA, Lauder JM (1998) Chronic cocaine treatment alters social/aggressive behavior in Sprague-Dawley rat dams and in their prenatally exposed offspring. Ann NY Acad Sci 846:399-404.

Krömer SA, Keßler MS, Milfay D, Birg IN, Bunck M, Czibere L, Panhuysen M, Pütz B, Deussing JM, Holsboer F, Landgraf R, Turck CW (2005) Identification of glyoxalase-I as a protein marker in a mouse model of extremes in trait anxiety. J Neurosci 25:4375-4384.

Landgraf R, Neumann ID (2004) Vasopressin and oxytocin release within the brain: a dynamic concept of multiple and variable modes of neuropeptide communication. Front Neuroendocrinol 25:150-176.

Landgraf R, Wigger A (2002) High vs low anxiety-related behavior rats: an animal model of extremes in trait anxiety. Behav Genet 32:301-314.

Landgraf R, Neumann I, Holsboer F, Pittman QJ (1995) Interleukin 1- $\beta$ 
stimulates both central and peripheral release of vasopressin and oxytocin in the rat. Eur J Neurosci 7:592-598.

Liebsch G, Landgraf R, Gerstberger R, Probst JC, Wotjak CT, Engelmann M, Holsboer F, Montkowski A (1995) Chronic infusion of a CRH1 receptor antisense oligodeoxynucleotide into the central nucleus of the amygdala reduced anxiety-related behavior in socially defeated rats. Regul Pept 59:229-239.

Liebsch G, Montkowski A, Holsboer F, Landgraf R (1998) Behavioural profiles of two Wistar rat lines selectively bred for high or low anxiety-related behaviour. Behav Brain Res 94:301-310.

Lonstein JS, Simmons DA, Stern JM (1998) Functions of the caudal periaqueductal gray in lactating rats: kyphosis, lordosis, maternal aggression, and fearfulness. Behav Neurosci 112:1502-1518.

Lubin DA, Elliott JC, Black MC, Johns JM (2003) An oxytocin antagonist infused into the central nucleus of the amygdala increases maternal aggressive behavior. Behav Neurosci 117:195-201.

Maestripieri D (1999) The biology of human parenting: insights from nonhuman primates. Neurosci Biobehav Rev 23:411-422.

Maestripieri D, D’Amato FR (1991) Anxiety and maternal aggression in house mice (Mus musculus): a look at interindividual variability. J Comp Psychol 105:295-301.

Manning M, Kruszynski M, Bankowski K, Olma A, Lammek B, Cheng LL, Klis WA, Seto J, Haldar J, Sawyer WH (1989) Solid-phase synthesis of 16 potent (selective and nonselective) in vivo antagonists of oxytocin. J Med Chem 32:382-391.

Mantella RC, Vollmer RR, Li X, Amico JA (2003) Female oxytocin-deficient mice display enhanced anxiety-related behavior. Endocrinology 144:2291-2296

McCarthy MM, McDonald CH, Brooks PJ, Goldman D (1996) An anxiolytic action of oxytocin is enhanced by estrogen in the mouse. Physiol Behav 60:1209-1215.

Neumann I, Russell JA, Landgraf R (1993) Oxytocin and vasopressin release within the supraoptic and paraventricular nuclei of pregnant, parturient and lactating rats: a microdialysis study. Neuroscience 53:65-75.

Neumann ID (2002) Involvement of the brain oxytocin system in stress coping: interactions with the hypothalamo-pituitary-adrenal axis. Prog Brain Res 139:147-162.

Neumann ID (2003) Brain mechanisms underlying emotional alterations in the peripartum period in rats. Depress Anxiety 17:111-121.

Neumann ID, Wigger A, Liebsch G, Holsboer F, Landgraf R (1998) Increased basal activity of the hypothalamo-pituitary-adrenal axis during pregnancy in rats bred for high anxiety-related behaviour. Psychoneuroendocrinology 23:449-463.

Neumann ID, Wigger A, Torner L, Holsboer F, Landgraf R (2000a) Brain oxytocin inhibits basal and stress-induced activity of the hypothalamopituitary-adrenal axis in male and female rats: partial action within the paraventricular nucleus. J Neuroendocrinol 12:235-243.

Neumann ID, Torner L, Wigger A (2000b) Brain oxytocin: differential inhibition of neuroendocrine stress responses and anxiety-related behaviour in virgin, pregnant and lactating rats. Neuroscience 95:567-575.

Neumann ID, Krömer SA, Toschi N, Ebner K (2000c) Brain oxytocin inhibits the (re)activity of the hypothalamo-pituitary-adrenal axis in male rats: involvement of hypothalamic and limbic brain regions. Regul Pept 96:31-38.

Neumann ID, Toschi N, Ohl F, Torner L, Krömer SA (2001) Maternal defence as an emotional stressor in female rats: correlation of neuroendocrine and behavioural parameters and involvement of brain oxytocin. Eur J Neurosci 13:1016-1024.

Neumann ID, Wigger A, Krömer S, Frank E, Landgraf R, Bosch OJ (2005)
Differential effects of periodic maternal separation on adult stress coping in a rat model of extremes in trait anxiety. Neuroscience 132:867-877.

Numan M (1994) Maternal behaviour. In: The physiology of reproduction, Ed 2 (Knobil E, Neill JD, eds), pp. 221-301. New York: Raven.

Numan M, Insel TR (2003) Hormones, brain and behavior. The neurobiology of parental behavior (Ball GF, Balthazart J, Nelson RJ, eds). Secaucus, NJ: Springer.

Nyberg JM, Vekovischeva O, Sandnabba NK (2003) Anxiety profiles of mice selectively bred for intermale aggression. Behav Genet 33:503-511.

Ohl F, Toschi N, Wigger A, Henniger MS, Landgraf R (2001) Dimensions of emotionality in a rat model of innate anxiety. Behav Neurosci 115:429-436.

Parmigiani S, Palanza P, Rogers J, Ferrari PF (1999) Selection, evolution of behavior and animal models in behavioral neuroscience. Neurosci Biobehav Rev 23:957-969.

Paxinos G, Watson C (1998) The rat brain in stereotaxic coordinates, Ed 4. Sydney: Academic.

Pedersen CA, Boccia ML (2002) Oxytocin links mothering received, mothering bestowed and adult stress responses. Stress 5:259-267.

Pellow S, Chopin P, File SE, Briley M (1985) Validation of open:closed arms entries in an elevated plus-maze as a measure of anxiety in the rat. J Neurosci Methods 14:149-167.

Rosenblatt JS, Factor E, Mayer AD (1994) Relationship between maternal aggression and maternal care in the rat. Aggress Behav 20:243-255.

Salome N, Salchner P, Viltart O, Sequeira H, Wigger A, Landgraf R, Singewald N (2004) Neurobiological correlates of high (HAB) versus low anxietyrelated behavior (LAB): differential Fos expression in HAB and LAB rats. Biol Psychiatry 55:715-723.

Swanson LW, Kuypers HG (1980) The paraventricular nucleus of the hypothalamus: cytoarchitectonic subdivisions and organization of projections to the pituitary, dorsal vagal complex, and spinal cord as demonstrated by retrograde fluorescence double-labeling methods. J Comp Neurol 194: 555-570.

Veenema AH, Torner L, Maloumby R, Neumann ID (2004) Correlates of male aggressive behavior with stress coping in different animal models. World J Biol Psychiatry 5 [Suppl 1]:43.

Vyas A, Bernal S, Chattarji S (2003) Effects of chronic stress on dendritic arborization in the central and extended amygdala. Brain Res 965:290-294.

Wigger A, Sanchez MM, Mathys KC, Ebner K, Frank E, Liu D, Kresse A, Neumann ID, Holsboer F, Plotsky PM, Landgraf R (2004) Alterations in central neuropeptide expression, release, and receptor binding in rats bred for high anxiety: critical role of vasopressin. Neuropsychopharmacology 29:1-14.

Windle RJ, Shanks N, Lightman SL, Ingram CD (1997) Central oxytocin administration reduces stress-induced corticosterone release and anxiety behavior in rats. Endocrinology 138:2829-2834.

Windle RJ, Kershaw YM, Shanks N, Wood SA, Lightman SL, Ingram CD (2004) Oxytocin attenuates stress-induced c-fos mRNA expression in specific forebrain regions associated with modulation of hypothalamopituitary-adrenal activity. J Neurosci 24:2974-2982.

Young LJ, Muns S, Wang Z, Insel TR (1997) Changes in oxytocin receptor mRNA in rat brain during pregnancy and the effects of estrogen and interleukin-6. J Neuroendocrinol 9:859-865.

Young III WS, Shepard E, DeVries AC, Zimmer A, LaMarca ME, Ginns EI, Amico J, Nelson RJ, Hennighausen L, Wagner KU (1998) Targeted reduction of oxytocin expression provides insights into its physiological roles. Adv Exp Med Biol 449:231-240. 